\title{
Address Half of the Population and Economic Development in India
}

\author{
Dr. Dhani Ram Agarwal ${ }^{1}$, Preeti Rustagi ${ }^{2}$ \\ ${ }^{1}$ School of Commerce \& Management, Faculty of Commerce, Starex University, Gurugram, Haryana, India \\ dragarwal1040@gmail.com \\ ${ }^{2}$ School of Commerce \& Management, Faculty of Commerce, Starex University, Gurugram, Haryana, India \\ preetirustagi11@gmail.com
}

\begin{abstract}
Right from our birth we remember our mothers whenever there is a pain of any kind. Our mother is not there, she is in heaven but hardly a single day passes when we do not remember our mother. This is true at least in our country without any discrimination on the lines of caste, education, religion etc. The beauty of a mother is that she does not expect in return from her children, although she has made several sacrifices for the welfare of the family. It does not mean that an attempt is being made to undervalue the mothers of other countries. These services are unilateral like transfer payments in national income accounting. Her services are takenfor granted (out of love, blessings, affection, and duty). Of course, they are valuable. In normal times they look after their small farms, manage their cattle and other livestock. They contribute to agriculture operations, they are also small manufacturers doing weaving, garments making or embroidery. All domestic services are rendered by them right from cooking to child care. We have several pen portraits of struggle and deprivation a million times and one gets to see the invisible face of hunger, that is really a face of woman from the most disadvantageous section of the society. They are poor and poverty has its multi-dimensional approach. Some women volunteers and NGOs are there to help. They talk about women empowerment, gender sensitisation, inclusive growth, women education, awareness etc. Several Institutions and Agencies Government and Non-Government and persons have come on the Scene but still much has to be done for the development of Women. Dr Raghuvansh Parsad who died at the age of 74 was the teacher of Mathematics but was quite aware of ground realities of India and he was the person, who did a lot as a Minister of Rural Development. He was instrumental in launching schemes known as Mahatma Gandhi National Rural Employment Guarantee Act but the situation is not better for hungry women and children living in the slums of urban India. They are also hiding their faces. Prime Minister Garib Kalyan Yojna is also a welcome step. Family wise, they are creating virtuous circles but the opportunity cost is that they are creating vicious circles for themselves. These vicious circles are to be broken for a balanced development of India. An attempt has been made to highlight the issues related to women development.
\end{abstract}

Keywords: Vulnerable section, Social taboos, Awareness

\section{Introduction}

Many of the girl children are out of school even after more than seven decades of our independence in 1947 Economic distress is mainly responsible for their malnutrition and other related important health indicators still a girl child is not considered a priority in the family when it comes to the distribution of available resources. From the most vulnerable sections they are forced/ pushed to act as child labour to supplement their family incomes. These people are not aware of their rights and rules of the land that is why they are prone to be exploited by their employers. Cases are found when these children are given in hands of middlemen for having a better life elsewhere.

It is deplorable that menstruation and the conversation around it have been shamed for centuries. Now there is no need for code words for the period. A bodily function that propelled the human race is rendered unspeakable by traditions of social taboo. The situation is that it is still considered by traditions of social taboo and code words are used. Prime Minister Narender Modi talked about menstrual hygiene in his Independence Speech on 15th August 2020. NGOs are working to spread awareness to break the taboo. Even, there is a movement demanding sick leave every month for workers just like maternity leave ${ }^{1}$. Top leaders (Political, Religious, Bollywood etc.) are coming to speak freely on issues like early marriages, and subsequent early pregnancies, exploitative employers, sexual and substance abuse and trafficking etc. the issues of hunger, malnutrition, safety and security of children particularly of girls, maternal mortality, child mortality, infant mortality, social problems like honour killing of girls, dowry deaths, promotion of girl education, opportunities for upgrading their skills through intensive training programmes to make them employable, higher education programmes access to health facilities and sanitation, cultural and economic impact after marriage etc. are on the cards through awareness programmes being undertaken by the govt. agencies and Depts. And other social organisations working for women development. Women empowerment is based on seven indicators namely (1) economic independence no compulsion and pressure from any other person including well meaningful family members (2) improvement in the standard of living (3) understanding of banking operations, (4) skill up-gradation, leadership (5) public relation (6) social participation and self-expression (Part and parcel in the decision-making process) (7) social participation attempts are being made in educational institutions for enhancing attributes likes gender sensitisation, self-respect, dignity self-esteem etc. New education policy 2020 will work as a catalytic agent.

Martin Luther King Junior has rightly said: "Intelligence + Character that is the goal of true education." India has been unfortunately divided in two parts- Awarded with resources and not awarded i.e. with scanty resources. These gaps and gulfs are to be filled in. 
The COVID-19 has hit women and girls differently and disproportionately. there is increased feminisation of poverty, domestic work and care burden and also a rise in domestic violence, marginalised women cannot access health care, family planning and education and millions have lost jobs and income - women socio-economic identifies race, religion, caste, age, class, multi-dimensional poverty, rural/urban, and migrant states - interest compounding gender discrimination "2

Robert Mcnamara the Governor of World Bank in Feb. 1970- 'the failure of GNP growth rate as an index of economic development said, "In the developing world, at the end of the decade, malnutrition is common, infant mortality rate is high, life expectancy is low) illiteracy is widespread unemployment is endemic and growing the redistribution of income wealth is severely skewed." These words are words of wisdom when India has experienced negative growth of high magnitude of $23.9 \%$ in the first quarter of 2020-21.

\section{Literature Review}

The real spirit in gender studies was provided by the UN declaration of the decade for women (1976-85). Since then various wings of the United Nation have been involved in gender studies in general and the role of women in particular in many parts of the world. The book, Gender, economic growth and poverty (market growth and state planning in Asia and the Pacific, by Noeleen Heyzer, Gita sen etc. for women and International Books - The Neither Lands) provides an in-depth study of the process of economic development initiated either by the market mechanism and resultant consequences for gender equity and poverty situations in selected countries of South Asia, South East Asia- Pacific counters including socialist countries like Vietnam and China. The book has been edited with a women's perspective in mind of the 14 essays contributed by 17 scholars as many as 12 are women including both the editors. Majority of the contributors are either sociologists or economists and have been intensely involved with the process of development as experienced with countries of their research work. The theme of the book is women and poverty. Economic development as engineered for state planning or the market mechanism has in almost all developing countries either marginalised or bypassed women. Gender equity has never been a target in any development models, particularly in the early stages. As expected, market type development caring more efficiency and productivity have been very harsh towards women in general and more so women and poverty. On the contrary, a state-led phased development is expected to be less efficient in allocating resources but more equitable in distributing the gains obtained from development. According to Noeleen Heyzar - the pattern of growth and economic management may be more important but simply the rate of growth is affecting a society's ability to deal with poverty. The distributional structures along with gender, class and ethnicity and their changes affect resource allocation and access to development benefits in a particular society and are access to development benefits in a particular society and are very important factors to consider. Also, problems of the break down in social cohesion and of corruption are well known in many countries and affect their ability to tackle poverty and issues of equity and the seething in hopelessness frustration and despair.

The types of state-led development that can have a positive effect on gender equity are those that have invested in social development, thereby increasing the involvement of women in terms of education and training: those that have introduced and upheld health and safety regulation provided services like sanitation, transportation, and child care, the legal and institutional framework for the regulation of the market so that entitlements of the poor may be strengthened through better access and protection the recognised women as citizens in their own right and not merely dependents target groups or instruments of development those that recognise poor women's productive and reproductive roles.

Women in most developing countries play a multifaceted role, from looking after the household to childbearing, to income earnings to participating in social and cultural life. They are constrained by limited access to education, health care, labour market participation to credit resources to jobs in the formal sector to decision making process to everything also that one can think of they are regarded as reproducers and shocked for all man-made calamities. They lack empowerment and entitlement and are powerless, most unsecured, oppressed and exploited. The govt. has initiated several programmes and policies for social development to overcome the above constraints to women's existence.

\section{Research Gap}

The national policy of education 1986 and its programme of action (POA) 1992 laid a special emphasis on the positive interventionist role that education must play in empowerment. It was expected that teachers should act agents of change in bringing attitudinal change in boys and girls. To confidence self-respect and to hasten the process decision making among them empowerment means to create awareness among students about gender issues and to enable them to destroy myths about any gender and to understand the equality of all development activities. If a primary survey is conducted in rural and urban areas of India either the society is male-dominated or female-dominated, in other words, leadership is not jointly shared. Since authors of this paper are associated with many social organisations, they have the opportunity to meet many persons both in rural and urban areas. They have the chance to regularly interact with some persons without any discrimination based on caste, community, region, religion, socio-economic status etc. Authors also had the chance to meet several women in Mewat Area ( one of the most backward district of India, located in Haryana) they could not answer a very simple question ( Total number of their children) without taking the permission of their husbands. They do not have any say in the decision-making process. All decisions are taken by their husbands and simultaneously authors have also visited many families where the husbands are not given an opportunity even to speak. All information is shared by the lady of the house, when husbands and wives both sit together to take any decision, normally they do not conclude except there is a fight between them. There are a few families, where decisions are taken jointly in a cordial way and even they consult their old parents and value their opinions. Hence 
empowerment should not be limited to women. That is empowerment is not mutually exclusive.

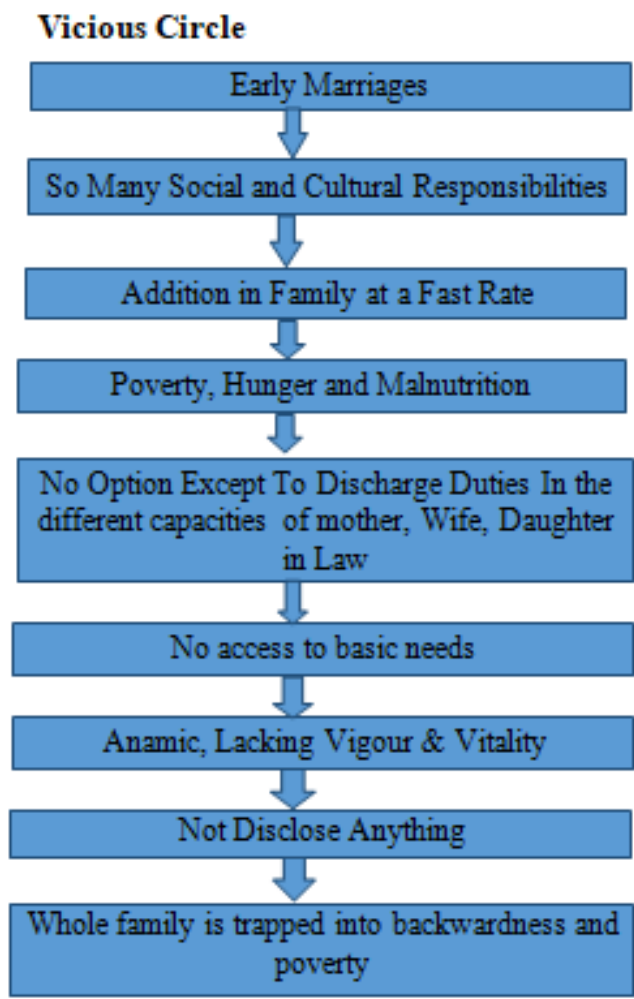

Figure 1

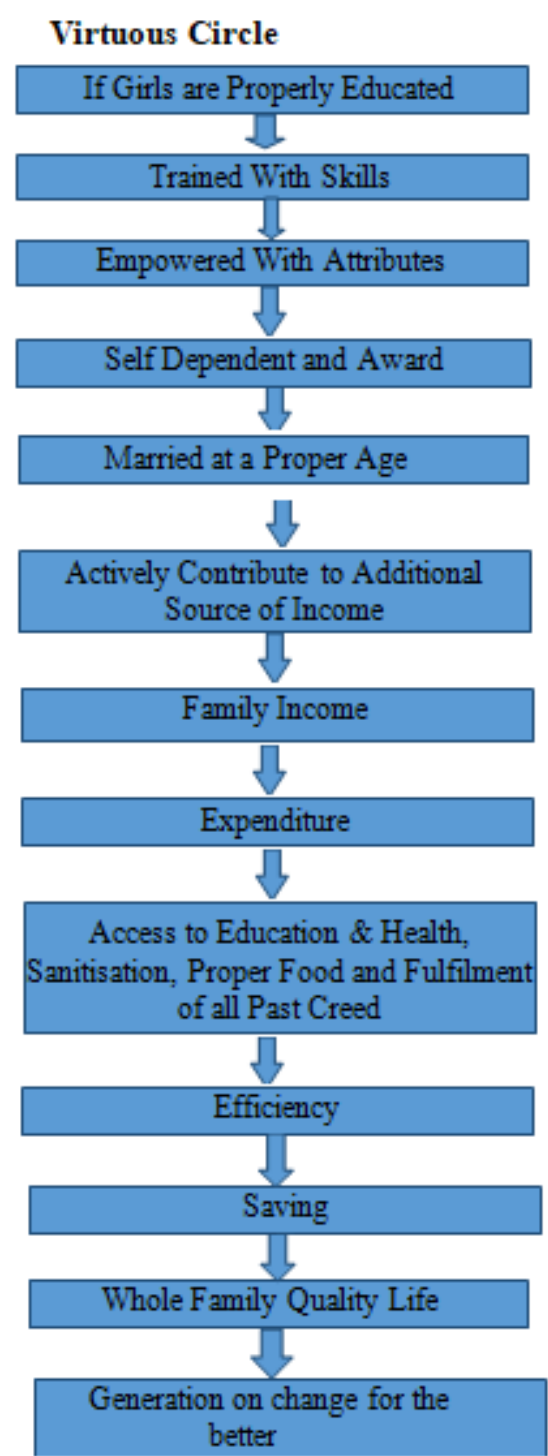

Poverty and underdevelopment are thus synonyms. Poverty is a curse but a great curse is backwardness because it is very difficult to break vicious cycles of backwardness - it has its cumulative effect/ Most of the people develop with a habit of accepting what happens to exist rather than to change an attitude of resignation and adopt the idea of innovations. NEP-2020 emphasis on foundational literacy and numeracy is worth appreciating and several entries and exist points are also available.

\section{Research Methodology}

Authors long association with some social organisations and their approach to the development of the marginalised section of the society along with still prevailing crimes against women have given birth to this research paper. Still, some of the girls reading in a college or university are not very careful about hygiene and health conditions (Maybe due to the lack of awareness of parents) Claim cannot be made that the study has been made on the primary information because there was no structured questionnaire and research design but the objectives were very clear. Our dependence has been mainly based on the secondary information obtained from standard research work published in mainly daily HT. Descriptive statistics and its tools have been used for making our interpretations. Nowadays, people are jumping on conclusions without having authentic information.

\section{Objectives}

The following are the main objectives of this paper

1) To study the global gender gap report 2020

2) To examine some research studies with special reference to India

3) To highlight the importance of half population in India

\subsection{Objective 1.1:}

The world economic forum (WEF's global gender gap report2020 reveals that it will take almost a century to achieve full parity at the current pace. The disparity is particularly striking in India. It ranks 112 out of 153 countries on the overall Global Gender Gap Index. The 
Covid 19 pandemic seems to have applied some brakes in several areas where workplaces were becoming more diverse as well as areas where access to resources across gender had become more equitable. The pandemic has hit the most vulnerable the hardest making these disparities worse. Oxfam India has estimated that the economic loss from women losing their jobs during this pandemic at nearly $£ 1216$ billion. Women account just $14 \%$ of leadership roles and $30 \%$ of professional and technical workers. We have not made much progress in terms of leadership roles at the chief executive officer level. India has the third-lowest rank on the Asia- Pacific in CEO representation (2\%), the second-lowest rank for female chief financial officer (CFO) representation $(1 \%)$ ranked 23 globally, India's female representation on boards increased by $4.3 \%$ over the past five years to $15.2 \%$ in 2019 . the global average is $20.6 \%$ in the 2019 master card index of women entrepreneurs India ranked 52 among 58 countries. Women business owners as a percentage of all businesses account for $38.2 \%, 37.9 \%$ and $36 \%$ respectively in Uganda, Ghana and Botswana ${ }^{3}$.

India has dropped two spots on the HDI ladder according to 2020. HDI report published by the UNDP on Dec. 16, 2020.
Asia's third largest economy ranked 131 among 189. India has slipped two places on the ladder because of quality of health (malnutrition and hunger) education and adverse sex ratio.

Long existing inequalities and social disparities have sharpened on gender lines and in access to resources including foods education and healthcare.

It is found that where women work that economies grow rapidly, those countries prosper. This all raises one question why India cannot reach one of the highest levels of women's entrepreneurship. The answer is only one- empowering the greater $50 \%$.

\subsection{Objective 1.2}

As per the report published in Daily Hindustan Times, Feb 16th, 2020 page 14, if we just compare some of the indicators with our neighbour Bangladesh the following is our position ${ }^{4}$ :

Table 1

\begin{tabular}{|c|c|c|c|c|c|}
\hline \multirow[t]{2}{*}{ S.NO. } & \multirow[t]{2}{*}{ Indicators } & \multicolumn{2}{|c|}{ India } & \multicolumn{2}{|c|}{ Bangladesh } \\
\hline & & Male & Female & Male & Female \\
\hline 1. & Life Expectancy (Average) & 67 & 70 & 71 & 74 \\
\hline 2. & NEO Natal MR & \multicolumn{2}{|c|}{ 22.73 Per Thousand Births } & \multicolumn{2}{|c|}{ 17.12 Per Thousand Births } \\
\hline 3. & IMR & \multicolumn{2}{|c|}{29.94} & \multicolumn{2}{|c|}{25.14} \\
\hline 4. & Under the Age of 5 Mortality Rate & \multicolumn{2}{|c|}{38.69} & \multicolumn{2}{|c|}{30.69} \\
\hline 5. & Literacy Rate & \multicolumn{2}{|c|}{$66 \%$ (Girls Above the Age of 15$)$} & \multicolumn{2}{|c|}{$71 \%$ (Girls Above the Age of 15) } \\
\hline 6. & Female Labour Parcipation & \multicolumn{2}{|c|}{$23 \%$ (8\% Drop in Last Decade) } & \multicolumn{2}{|c|}{$30 \%$} \\
\hline
\end{tabular}

In India, women represent only $29 \%$ of the labour work done in India because it is unpaid (almost it is informal) they comprise $40 \%$ of agricultural labour, they control $9 \%$ of land and still, about $50 \%$ of India's women do not have a bank account and $60 \%$ of women do not have a bank account and $60 \%$ of women have no valuable assets in their name (subject to variations, more than half of the work done). They are the victims of violence with the rate of crimes against women at $53.9 \%$.

India recorded a $1.6 \%$ rise in the number of cognizable crimes between 2018 and 2019, according to the latest crime in the report by the National Crime Records Bureau (NCRB)
1) Crime against women increased by $7.3 \%$ - Crime against women, children, senior citizens and people belonging to the scheduled caste and scheduled tribe communities' increase between 2018 and 2019 at varying degrees. Crimes against women increased by $7.3 \%$ in the last year (2019)

Table 2: Crimes-- (in Thousand)

\begin{tabular}{|c|c|c|c|c|c|}
\hline Year & $\begin{array}{c}\text { Against } \\
\text { women }\end{array}$ & $\begin{array}{c}\text { Against } \\
\text { Children }\end{array}$ & $\begin{array}{c}\text { Against } \\
\text { Senior } \\
\text { citizens }\end{array}$ & $\begin{array}{c}\text { Against } \\
\text { Scheduled } \\
\text { Castes }\end{array}$ & $\begin{array}{c}\text { Against } \\
\text { Scheduled } \\
\text { Tribes }\end{array}$ \\
\hline 2018 & 378.2 & 141.8 & 24.3 & 42.8 & 6.5 \\
\hline 2019 & 405.9 & 148.2 & 27.7 & 45.9 & 8.3 \\
\hline
\end{tabular}




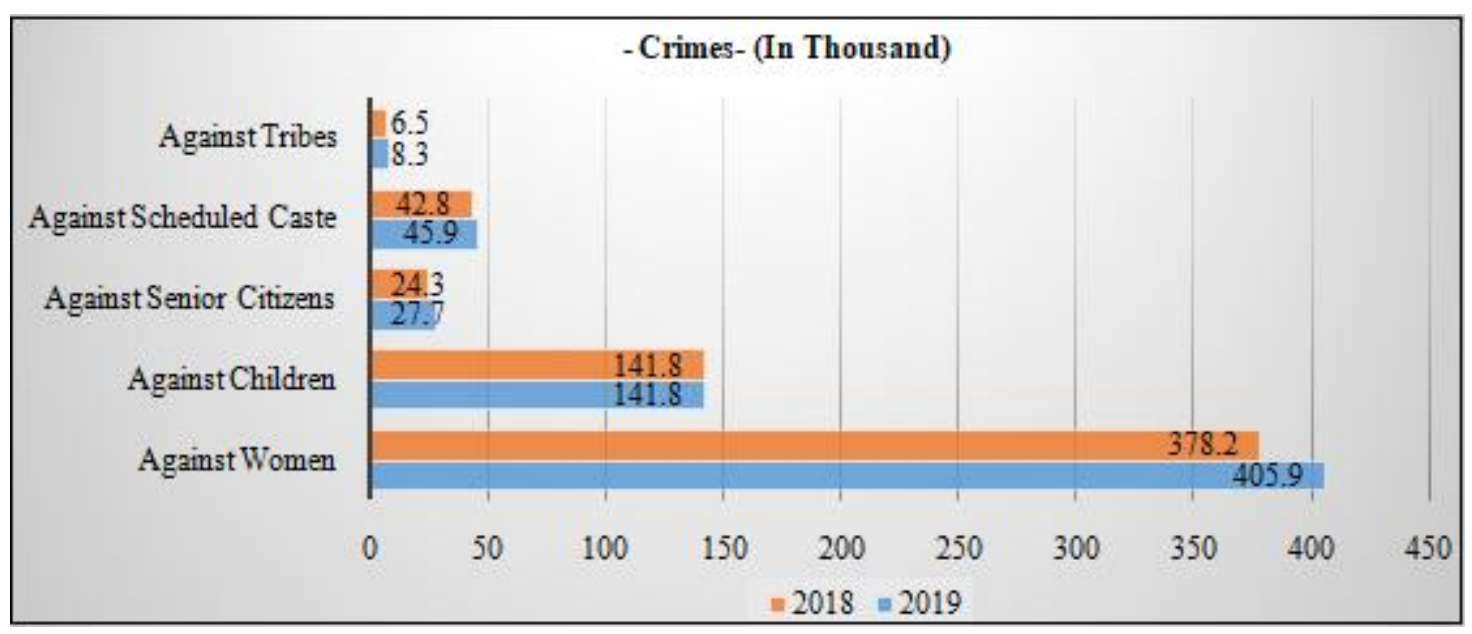

\section{Graph 1}

2) Crime against women, cruelty by Relatives: Most common cruelty by the husband or his relatives was the most committed crime against women in 2019 comprising $37 \%$ of all crimes against women. Rape comprised about $8 \%$.

Type of Crime

$\%$ in crimes against women

- Cruelty by husband 30.9

- Assault on women with intent to outrage her modesty 21.8

- Kidnapping and abduction of women 17.9

- Rape

7.9

- Others

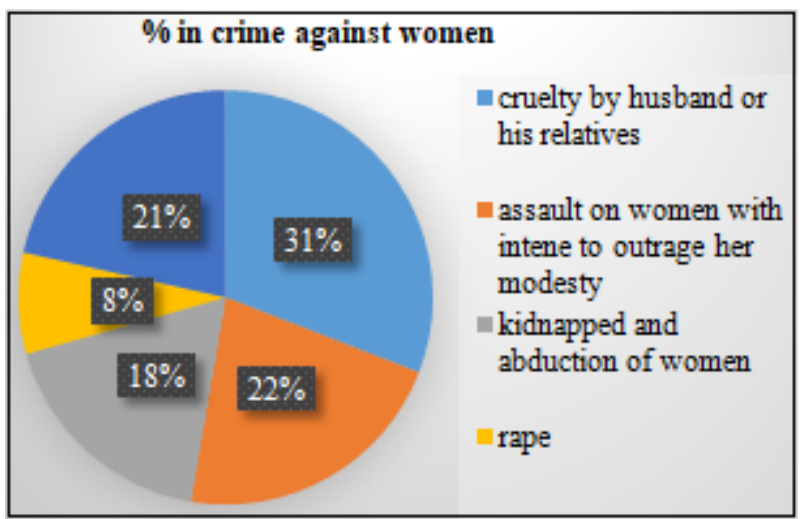

Graph 2: Source: Daily HT October 01, 2020, Page 02

The struggle for gender equality has understood daily focussed on women. Their health, their awareness, their education. According to Nishtha Satyam, who heads UN women in India, Bhutan, Maldives and Sri Lanka- we missed the most critical pillar of change- men- we need men who recognise the housework is equally a man's job.

According to Lalita Panicker in her write up, ensure the safety of vulnerable children, published in Daily HT Dated 23 August 2020, Page 10.

Children are also often caught in the situation of domestic violence which is rising at this to me with women being trapped at home and frustration and anger levels among former bread winders being exacerbated. Many children are living with relatives as their parents migrate to cities to look for work making them with very little support even from non-government organisations leaving them open to sexual and substance abuse and trafficking." The national commission of women reported an exponential rise, the largest in a decade noting a third of 13410 complaints including 4350 domestic violence were filed during the lockdown (Namita Bhandare- "Covid A distressing spike in violence '’Daily HT dated 12 Dec. 2020 Page 16.

\subsection{Objective 1.3}

Any pandemic or pain in life has no meaning when there is family love. It could be the best antidote to pain. Sometimes medicines do not work much when the whole family is standing by your side. There is no way you can let hope slip through your fingers. The half population is not equally important but more important there are cycles in the family, ups and downs. They are very important to learn so many things from the experience of our old parents, particularly mothers. This half population is our Brahma, Vishnu and Shiva- the whole universe.

It has also been observed that there are certain areas in India where the population is outnumbered by its deities so it makes sense that during that times of distress they turn to solace. That is why they do not care for taking a bath every day, no needs of soaps (washing feet and cleansing hands with ashes from the hearth before cooking or eating is customary) and they do not wear masks. Their strong belief is that there is a hot-tempered deity, which is responsible for this Covid-19 Pandemic. In tribal areas, the nationwide lockdown had no implications and they went about their daily activities as usual. During the senior author's childhood, there was no treatment for measles, smallpox, chickenpox etc. Only one treatment was there to worship Goddess Sheetla.

\section{Conclusion}

There are challenges and opportunities which are considered bi-products. If any researcher goes to a backward area, he or she will find that woman is very good paymaster. They are very particular in repayment of loans along with the due rate of interest. It is observed that women enterprises can generate several jobs. Micro enterprises led by women require training programmes such as financial and digital literacy. Hand holding workshops could also be arranged according to their convenience. A wide network of self-help 
groups is needed throughout the country. A conclusion may be drawn in the words of Sangeeta Reddy, " ........longexisting inequalities and social disparity have sharpened on gender lines and in access to resources including food, education and health care." (Daily HT boosting Women Entrepreneurship and economic leadership, Sept 17, 2020, Page 12)

\section{Suggestion}

1) Through education, a scientific temperament may be developed among women, rather than a traditional approach of thought process without any logic. Rest all problems would be taken care of.

2) If we compare the ratio of estimated female to male earned income ratio is about .35 , while it should have gone to more than .6.e

3) A first of its kind National Statistical office report released on $20^{\text {th }}$ Sept 2020, the average Indian woman spend 243 minutes (a little over four hours on house hold work and domestic chores man does. Men spend more time than women in other themselves.

4) There seems to be an inverse relationship women on household chores but a direct one between age and time spent by men on these activities.

Where does the time go (minutes?)

Table 5

\begin{tabular}{|c|c|c|}
\hline & Urban women & Rural women \\
\hline Employment & 62.4 & 60.7 \\
\hline Unpaid work and care going & 275.8 & 317.4 \\
\hline Socialising and Idling & 147.1 & 160.9 \\
\hline Personal Care & 67.6 & 70.0 \\
\hline Eating and drinking & 97.2 & 94.5 \\
\hline Mass media use & 1059 & 61.1 \\
\hline Sleeping & 552.3 & 557.3 \\
\hline Learning & 87.8 & 82.0 \\
\hline Others & 47.8 & 36.1 \\
\hline
\end{tabular}

When we calculate standard deviation of urban women scheduled it comes out to be 152 and for rural women it is 162 therefore, there is large variation in the schedule of rural women.

\section{References}

[1] Daily HT, Aug 26, 2020, page 12

[2] Daily HT, Aug 9, 2020, Page 10

[3] Daily HT, September 18, 2020 Page 12

[4] Daily HT, Feb 16, 2020, Page 14

[5] Daily HT, Aug 23, 2020, Page 10

[6] Daily HT, October 1, 2020, Page 02

[7] Daily HT September 17, 2020, Page 12

[8] Daily HT, September 30, 2020, Page 1

[9] Daily HT, September 30, 2020, Page 12

[10] Daily HT October 16, 2020, Page 13.

[11] Daily HT September 30, 2020, Page 1

[12] www.worldwidejournals.com

[13] jounals.sagepub.com

[14] www.theigc.org

[15] www.ncbi.nlm.nih.gov

[16] October 18, 2020, Daily HT, Page 13
[17] Daily HT dated 12 Dec. 2020 Page 16

The necessary and sufficient conditions of a balanced approach to development are hidden in addressing the issues of our half population at the earliest. 